\title{
Niche partitioning on Sumatran Elephant (Elephas maximus sumatranus) and human in space and resources in Riau, Indonesia
}

\author{
YOHANES WISNU SUKMANTORO ${ }^{1, \vartheta}$, HADI SUKADI ALIKODRA ${ }^{1}$, AGUS PRIJONO KARTONO ${ }^{1}$, \\ EFRANSJAH ${ }^{2}$ \\ ${ }^{1}$ Department of Tropical Biodiversity Conservation, Faculty of Forestry, Institut Pertanian Bogor. Jl. Dramaga Raya, IPB Campus, Bogor 16680, West \\ Java, Indonesia. Tel./fax.: +62-252-8621947, ,`email: wishnubio74@ gmail.com \\ ${ }^{2}$ Ministry of Environment and Forestry, Republic of Indonesia. Manggala Wanabakti Bld., Jl. Gatot Subroto, Central Jakarta 10207, Jakarta, Indonesia
}

Manuscript received: 1 March 2019. Revision accepted: 25 April 2019.

\begin{abstract}
Sukmantoro YW, Alikodra HS, Kartono AP, Efransjah. 2019. Niche partitioning on Sumatran Elephant (Elephas maximus sumatranus) and human in space and resources in Riau, Indonesia. Biodiversitas 20: 1362-1373. Research on elephant and human niches at Balai Raja and Tesso Nilo have been done for 6 years (2012-2017). The study was conducted by recording the distribution of elephants and communities. The distribution of elephants was identified through an installed GPS Collar in 3 groups of elephants (Butet, Angelina and Desma) since 2012. In 2016, data collection of resources was done through OLI 8+ Landsat imagery and records from the field. From the results of the study, elephants (Desma, Angelina and Butet groups) and humans have significantly different niches in space, but in terms of resources, all three elephant groups are almost the same to use them. In the context of niche partitioning of resources, Desma group used more thenatural forest, swamp and wasteland areas than the communities. InTesso Nilo, elephants groups used more open land than the communities.The overlapping between elephant and human creates human-elephant conflicts. For this reason, strengthening the niche partitioning strategy in space and resources can be a solution to conflict reduction. In addition, if elephants with humans are forced to live in the same space and resources, they develop strategies of neutralism or coexistence. For the community, converting plant commodities in the direction of an elephant's dislike (still of economic value) can reduce losses for the community and create a non-disturbing relationship between elephant and human. Examples of what the community has done are cassava cultivation and timber industry concession strategy in planting Acacia which is relatively not detrimental to the company even though the plant is damaged by an elephant.
\end{abstract}

Keywords: Elephant, human, niche, resources, space

\section{INTRODUCTION}

Niche is generally known as the response of species or individuals to the distribution of natural resources and competition (competitors) (Schoener 2009). At the time the species interact with other organisms in accessing resources, and there is temporal and spatial competition resulting in changes in certain factors in the species (Leibold and McPeek 2006; Peterson et al. 2011).

In the context of the niche of Hutchinson (1957), niches are multidimensional $\mathrm{N}$ spaces in which an organism lives in dividing its life from other organisms in terms of conditions of resources and environmental conditions. In the context of Hutchinson is a niche approach in spatial spectacles while Grinnel is in the context of ecological rules (Schoener 2009; Peterson and Soberon 2012). In the context of elephants, niches are seen from the dimensions of diet and habitat selection temporally and spatially. Spatially, the movement of elephants depends on the season and in the context of habitat niches, in the rainy season it is lower than the dry season (Ahrestani 2012). In the context of temporal niches, some species have a high overlap of African elephants in the use of water pools, but generally, they avoid these elephants (Valeix et al. 2007). This is due to interference competition and limited and localized resource availability. The division of time in the use of these resources is a herbivorous strategy where elephants are the strongest among others (Valeix et al. 2007).

Rood et al. (2010) stated that the forest cover of Sumatra Island is an important spatial area for Sumatran Elephants. Elephant niches concentrated in lowland tropical rain forests where food diversity for elephants is very diverse and optimal (Hedges et al. 2005; Azad 2006; Pradhan and Wegge 2007). So, the optimal niche for Sumatran Elephants is a region that has high-value forest cover with high productivity as well. Nevertheless, elephants use a larger landscape area than other mammal species, and the limitation of elephant movements is steep locations or slopes (Feng and Li 2005; Pan et al. 2009). In the study of Kamsi et al. (pers. comm. 2007 in Rood et al. 2010), the steep slope barrier is insignificant, Sumatran elephants can be identified up to an altitude of 1600 asl, and in Aceh (Ulu Masen), Sumatran elephants are identified through fresh feces up to an altitude of 2200 asl.

The main problem facing Sumatra Island in the last 20 years is the drastic decline of lowland rainforests as the most important Sumatran Elephant habitat. The lowland forest of Sumatra Island is the most rapidly degraded. Until 2012, Sumatra's lowland forests had only 4.5 million ha $(16.6 \%)$ of the total 26 million ha (Margono 2014; Uryu et al. 2008; Songer et al. 2012). The enormous land conversion in Sumatra is caused by land clearing for 
industrial plantations and oil palm plantations. The impact of land conversion on elephants is a decrease in habitat carrying capacity and finally human-elephant conflict (Songer et al. 2012). In many locations where elephant habitat is located, conflicts occur between elephant and human due to the seizure of land, dwellings or disturbing the community to gardening and farming. Human-elephant conflicts also left the death toll for both (Desai and Riddle 2015; Senthilkumar 2016).

Conflict becomes the biggest role of elephant and human life optimism, and the decline of conflict (interspecific competition or agonistic relationship patterns), the role of existence is low, and to encourage optimization of both is important (Polansky et al. 2013). In optimization, the strategy of dividing niches between elephant and human is one of the conditions. So, this can minimize the struggle for resources between elephant and human. Living things have a strategy not to conflict in terms of resources, so that spatially, niches coincide but temporally or altitudinal or food choices, they can be different (Valeix et al. 2007; de Silva et al. 2014).

In Riau (one of the provinces in Sumatra-Indonesia), the conflict of human elephants is a major problem for the conservation of elephants because this conflict causes the death of the elephant except in hunting. Current solutions to conflict reduction are to develop conflict mitigation units and elephant-eviction techniques. The main root of the actual conflict is due to the seizure of space, resources and decreasing habitat quality for elephants to eat, get water and minerals. This research focuses on the niche of space and resources between elephant and human to be able to know their niche situation. Management of niches in space and resources is expected as a solution also in handling human-elephant conflicts in Riau so that intervention strategies can be carried out to encourage niche management and improve the quality of resources in these locations.

\section{MATERIALS AND METHODS}

\section{Study area}

This research was conducted in 2012-2017 at Balai Raja (Bengkalis District, Riau Province) and Tesso Nilo (Pelalawan, Kampar and Kuantan Sengingi Districts, Riau Province) especially in terms of GPS Collar installation and interviews with people in these two locations between 2012-2016 and resource data collection conducted in 20162017. So the total area of the study area is 489,600 ha $\left(4896 \mathrm{~km}^{2}\right)$.

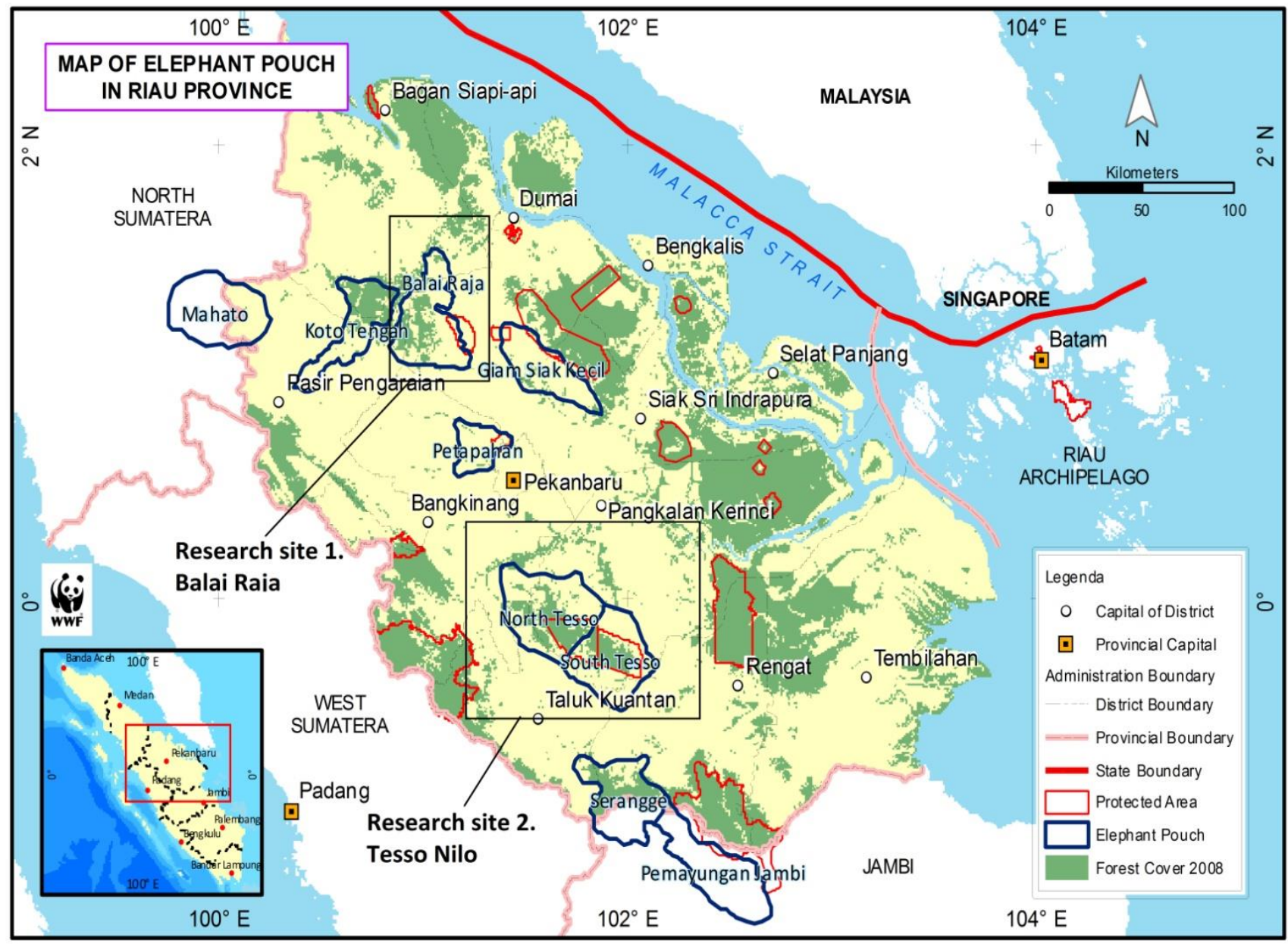

Figure 1. Land cover and research sites of elephant in Balai Raja and Tesso Nilo, Riau, Indonesia 
Table 1. Variables on the distribution of elephants-humans and resources at Balai Raja and Tesso Nilo research sites, Riau, Indonesia

\begin{tabular}{lll}
\hline \multicolumn{1}{c}{$\begin{array}{c}\text { Variables of } \\
\text { distribution }\end{array}$} & \multicolumn{1}{c}{ Balai Raja } & \multicolumn{1}{c}{ Tesso Nilo } \\
\hline $\begin{array}{l}\text { Elephant } \\
\text { distribution data }\end{array}$ & Feeding sites & Feeding sites \\
$\begin{array}{l}\text { Human } \\
\text { distribution data }\end{array}$ & Ponds & Ponds \\
& River & River \\
& Settlement & Settlement \\
& Factories & Factories \\
& Ex-factories & Public building \\
& Public building & Road/gate \\
& Oil sheld & Forest \\
& Road/gate & Oil palm plantation \\
& Forest & Open land \\
& Rubber & Wasteland \\
& Oil palm plantation & HTI Acacia or \\
& & Eucalyptus \\
& Open land & Shrubs \\
& Wasteland & \\
& Mix-agricultures & \\
Swamp & \\
\hline
\end{tabular}

Three GPS Collars were installed in three adult female elephants in Balai Raja (Desma elephant group) and Tesso Nilo (Angelina and Butet elephant groups) from 2012 to 2016. The installation team consisted of the initial survey team, several people who carry out elephant anesthesia, a veterinarian, and two people to measure elephant morphometry and safeguard catch locations as anticipation of other wild elephants going to the location. The installed GPS Collar was then monitored by the monitoring team through the www.awetelemetry.com website and was assisted by checking on the field by the elephant patrol team (The Threat Hunter).

For human distribution, surveys were carried out through data collection and interviews in Balai Raja and Tesso Nilo in a $2 \times 2 \mathrm{~km}^{2}$ grid. Human distribution and settlements are mapped in the grid cell. If the respondent and settlements are not found in the grid, the grid will be considered empty of the human population. Then, settlement data collection is also carried out and settlements are a sign of human existence. Resource collection in the field was taken in 2016-2017 in the area which was the distribution of community respondents in the previous data collection and 2018 was completed with resource data collection using the desk study using $8 \mathrm{OLI}+$ Landsat images, especially resources that can be identified through such images water, forest, oil palm plantation, rubber, swamp, open land, mixed fields and other land cover. River and road data uses RBI (Map of Indonesian Earth) in the form of shp.

Data that has been collected is then analyzed. Data on the distribution of elephants with GPS Collar and human distribution (respondents and settlements) were analyzed spatially (vectors) in a $2 \times 2 \mathrm{~km}^{2}$ grid. Then a separate distribution identified between elephant and human or overlapping elephants and humans per grid. Then, PCA (Principle Component Analysis) is a multivariate technique statistic that uses orthogonal transformations to convert a set of correlated variables into an orthogonal set, non-correlated axes are called principal components (James and McCulloch 1990; Legendre and Legendre 1998; Robertson et al. 2001; Gotelli and Ellison 2004). PCA can be used in analyzing niches. Data collected can be in the form of factors with several variables which are based on distance by factors or surface distance or proximity to trends in temperature, altitude, humidity and so on (Janžekovič and Novak 2012).

PCA requires normal data for each factor and variable. However, in the context of field data, normal distribution is often difficult to produce, so it needs to be transformed into n-1 first. Normal test data test is with Kosmolgorov Smirnov. To normalize the data, the transformation of the primary data sample values to $n-1$ (sample value) is used for that (Janžekovič and Novak 2012). If it cannot be done with $\mathrm{n}-1$, then cleaning outliers or data that is extremely high or low is cleared (Akhtar 2017).

Xlstat as a statistical software added in an excel program (add-in) is used to perform PCA analysis. From the statistical results, $\mathrm{N}=$ the amount of data collected is the value of the distance of the variable position to the distribution of elephants or humans, the minimum data value-maximum, the middle value (mean) and standard deviation generated in this analysis. Eigenvalue, variability and cumulative are also produced.

The measurement of the level of association between elephant and human based on space is done by calculating the Jaccard association index with the following relationship (Ludwig and Reynold; 1988).

$$
I J_{X Y}=\frac{a}{a+b+c}
$$

To test the presence or absence of associations in many species, it is necessary to calculate the chi-square distribution value $(\mathrm{W})$ with the relationship $\mathrm{W}=\mathrm{NVR}$. If the value of $\mathrm{W}$ lies in the distribution limit $\chi 2$ with a probability of $95 \%(\chi 20.025 \mathrm{~N}<\mathrm{W}<\chi 20.975 \mathrm{~N})$ this means there is no species association. If the $\mathrm{W}$ value is outside the distribution limit $\chi 2$ with a probability of $95 \%$ $(\mathrm{W}<\chi 20.025 \mathrm{~N}$ or $\mathrm{W}>20.975 \mathrm{~N})$, this means there is a species association.

To see niche overlap based on the distribution of resources, the Pianka 1973 index in Krebs 1999 can be used. The formula for the Pianka index is;

$$
P O_{a b}=\frac{\sum p_{a j} p_{b j}}{\sqrt{\sum p_{a j}^{2} \sum p_{b j}^{2}}}
$$

Where PO is the Pianka Overlap index, Paj is the use of resources for species a and $\mathrm{Pbj}$ is the use of resources for species b. In the Pianka index analysis, it is necessary to calculate the distribution value of chi-square (V) at the free degree (df) (s-1) (r-1) with the relationship V =-2Tln (GO). If the value of $\mathrm{V}$ exceeds the critical value of Chi-square at the real level of $5 \%$, this means there is an overlap of niches between species. If the value of $\mathrm{V}$ is smaller or equal 
to the chi-square critical value at the $5 \%$ real level, this means there is no overlap of the niche between the species.

\section{RESULTS AND DISCUSSION}

\section{Niche-based on space}

From the data collection in the field, the number of samples that have data on elephant distribution of GPS Collar attached to Desma's neck Balai Raja is 2028 samples $(\mathrm{N}=2028)$. Then in Tesso Nilo, the distribution of Angelina (GPS Collar attached) is 995 samples $(\mathrm{N}=995)$, and Butet (GPS Collar attached) is 1027 samples $(\mathrm{N}=1027)$. Desma's total daily movement monitored by the GPS Collar is 677 days starting from December 15, 2012, to January 6, 2015, then Angelina and Butet are each monitored by GPS Collar for 336 days (monitored until March 4, 2014) and 332 days (monitored until January 28, 2016). For human respondents, the number of respondents taken as samples at Balai Raja was 102 people $(\mathrm{N}=102)$ and for human respondents, at Tesso Nilo there were 99 people $(\mathrm{N}=99)$. Then the recorded settlement data at Balai Raja is 402 settlement points and 305 settlement points in Tesso Nilo.

Of the total grid $2 \times 2 \mathrm{~km}^{2}$ in MCP distribution of human and settlements in Balai Raja pouch (total is 284 grids) elephant roaming space is 70 grids, then human roaming space (derived from the total number of respondents and settlements) which is 90 grids. The overlap between elephant and human (respondents and settlements) is 42 grids. Of the relative percentage of elephant roaming space, it is $24.64 \%$ of the total grid of Balai Raja. The relative percentage of overlapping roaming space between elephant and human (based on the distribution of respondents and settlements) is $14.79 \%$. So the overlap of niches based on roaming space between the elephant Balai Raja (Desma elephant group, Gj Desma) and the community is only $14.79 \%$. Of the total grid used by elephants and humans, 185 grids were not used by both or around $61.056 \%$ of the reference MCP used.

In Tesso Nilo, two groups of elephants (Angelina and Butet elephant groups) have identified movements or distribution through the use of GPS Collar. By using a $2 \times 2$ $\mathrm{km}^{2}$ grid, the distribution of Angelina and Butet was identified together with the distribution of the community (respondents and settlements) at Tesso Nilo. Marking each distribution based on color differences on the grid. The distribution of Angelina elephant group ( $\mathrm{Gj}$ Angelina) is marked by the color of the light green grid and Butet elephant group ( $\mathrm{Gj}$ Butet) marked in light blue. The distribution of people (humans) is represented by respondents and settlements are colored orange. The overlap between Angelina and the community is marked by a red grid and between Butet and the community is marked by a yellow grid.
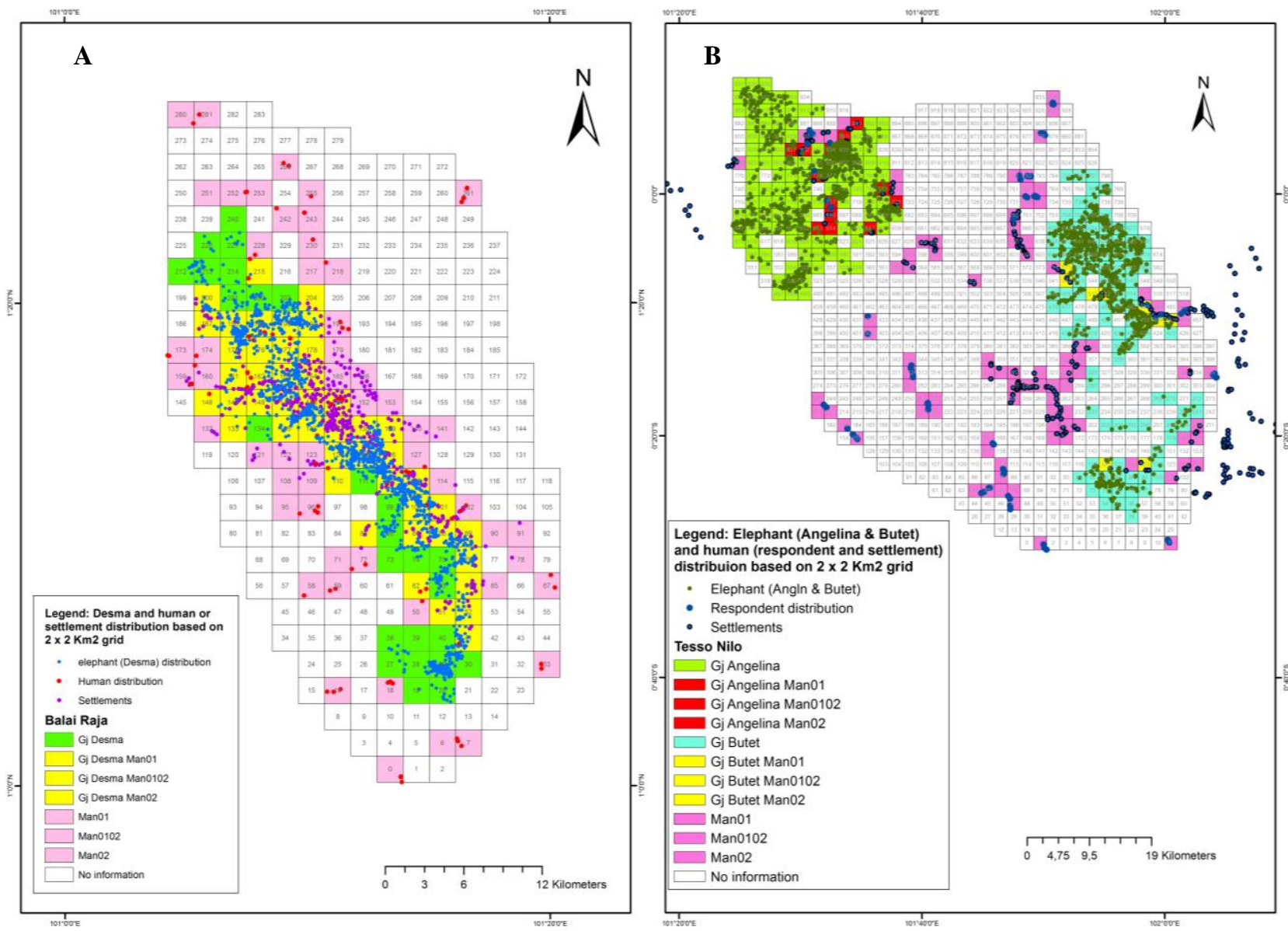

Figure 1. Desma and human distribution (respondents and settlements) in the $2 \times 2 \mathrm{~km}^{2}$ grid at the Balai Raja (A) and the distribution of Angelina, Butet and humans (respondents and settlements) in the $2 \times 2 \mathrm{~km}^{2}$ grid at Tesso Nilo (B), Riau, Indonesia 
The total grid for the two elephant groups is 940 grids. Of the total grid, 241 grids $(25.64 \%)$ were used for the distribution of the two elephant groups (Angelina were scattered in 129 grids and Butet was 112 grids). The distribution of respondents in the two elephant groups was 40 grids $(4.26 \%)$, while for settlements spread in 69 grids (7.34\%). The overlap between elephants and communities between elephants and community respondents and settlements is 22 grids $(2.34 \%)$. If the overlap between elephants and people (humans) is divided based on elephant groups, between Angelina and the community (respondents and settlements) are 12 grids (1.28\%) and between Butet and the community (respondents and settlements) have a grid number of 10 grid $(1.06 \%)$.

From the results of the study, $25.64 \%$ of the total grid area based on the MCP of the two elephant groups was relatively small from all the areas that elephants could explore. Then overlapping elephants with humans is also relatively small or only involves 12 grids and 10 grids for each group of elephants Angelina and Butet. To be able to be clearer about the condition of the distribution of elephants, the distribution of communities and overlapping habitat space between elephant and human or the Tesso Nilo community can be seen in Figure 1. The percentage of habitat space use in the $2 \times 2 \mathrm{~km}^{2}$ grid of the distribution of both or overlapping both can be seen in Table 2 . While, test the normality of data on all variables on elephants and human can be seen in Table 3 .

\section{Niche in resources}

The niche analysis is not only on the scale of space from the home range or movement or activity of elephants and humans, but also from the amount of resource use. Identified resources refer to resources that have been focused on as variables for PCA analysis. The resources in the PCA analysis are then divided into three categories of resources, namely infrastructure (factories, ex-factories, public facilities, settlements, oil fields and roads), needs for elephants (water bodies, natural forests, rivers and feed locations) and other land cover (natural forest, rubber, oil palm, swamp, bush, open land, wasteland, mixed gardens and Acacia or Eucalyptus).

At Balai Raja, the total resources identified were 16 resources, while in Tesso Nilo, 13 were identified. From the results of the study, the median closest distance between elephants and resources is 0 meters or in resources (elephants with Acacia or Eucalyptus in Tesso Nilo and humans by way of Balai Raja and Tesso Nilo). The farthest median is an elephant with a factory with a median of $41072.1 \mathrm{~m}(41.1 \mathrm{~km})$. All data distributions per variable are distributed close to normal but do not meet Gaussian standards (p-value <0.05). Nevertheless, PCA is still used in this study because the value of skewness and kurtosis ( -2 $<x<2)$ has indicated the normal distribution for each variable.

From the PCA analysis, the KMO in Figures 2.A-B (Desma with resources) is 0.564 , Chi quadrat (observation value) 35595.8 , Chi quadrat critical value 95.705, $\mathrm{DF}=$ 120 and $\mathrm{p}=$ value $<0.0001$ (alpha 0.95)). In Figures 2.C-D (Angelina and Butet with resources) are 0.668 (chi quadrat observation 7988.445, chi-quadrat critical values are 58.7 $(\mathrm{DF}=78)$ and $\mathrm{p}$-value $<0.0001($ alpha $=0.95))$. The KMO in Figures 2.E-F (Balai Raja community and resources) is 0.719 (Chi quadrat observation is 536,648 , chi quadrat critical value is 95.705 ( $\mathrm{DF}=120)$ and $\mathrm{p}$-value is $<0.0001$ $($ alpha $=0.95)$ ) and Figures 2.G-H (Tesso Nilo community with resources) is 0.50 (Chi quadrat observation is 622,091, chi quadrat critical values are 58,654 (DF $=78)$ and $\mathrm{p}$ value $<0,0001($ alpha $=0.95)$ ). All observation subjects have a p-value smaller than 0.0001 which means that there is at least one variable that has a strong correlation with the other variables. The overall KMO value is 00.50 or feasible for factor analysis.

Variables that influence the distribution of the Desma elephant group in Balai Raja, variables of wasteland, rivers, natural forests, oil palm and swamps whose position is closest to the movement of elephants with a value close to $0 \mathrm{~m}$. Open land, roads, settlements, rubber, and mixed gardens have values $<0.5$ (see Figures 2.A-B). Public facilities, feed locations, factories, water pools, oil fields, and former factories are 0.5 or away from elephant movements or in the farthest distance from elephants. In Tesso Nilo, the variables of rivers, Acacia, palm, shrubs, and settlements are closest to the distribution of Angelina and Butet compared to other variables. Variables that stay away from the distribution of Angelina and Butet are water pools, factories, public facilities, feed locations, and wasteland. In Figures 2.A-B, variables cluster or form clusters but natural forests have a solitary position and generally these variables have a negative correlation even though they are weak with natural forest.

Table 2. Relative percentage of use of space for elephants and human including the use of overlapping elephant and human space from the total grid in the MCP pocket of Balai Raja, Riau, Indonesia

\begin{tabular}{|c|c|c|c|c|c|c|}
\hline & \multicolumn{3}{|c|}{ Balai Raja } & \multicolumn{3}{|c|}{ Tesso Nilo } \\
\hline & $\begin{array}{c}\text { Number of } \\
\text { grid }^{\mathrm{a}}\end{array}$ & $\begin{array}{l}\text { Total } \\
\text { grid }^{b}\end{array}$ & $\begin{array}{c}\text { Relative } \\
\text { percentage }(\%)^{\mathrm{c}}\end{array}$ & $\begin{array}{c}\text { Number of } \\
\text { grid }^{\mathrm{a}}\end{array}$ & $\begin{array}{l}\text { Total } \\
\text { grid }^{b}\end{array}$ & $\begin{array}{c}\text { Relative } \\
\text { percentage }(\%)^{c}\end{array}$ \\
\hline Sb Gajah & 70 & 284 & 24.65 & 219 & 940 & 23.30 \\
\hline Sb Man01 & 47 & 284 & 16.55 & 36 & 940 & 3.83 \\
\hline Sb Man02 & 59 & 284 & 20.77 & 67 & 940 & 7.13 \\
\hline Sb Man0102 & 90 & 284 & 31.69 & 7 & 940 & 0.74 \\
\hline Gajah and Man0102 & 42 & 284 & 14.79 & 24 & 940 & 2.34 \\
\hline
\end{tabular}

Note: ${ }^{a}$ Number of grids used by elephants (seen from the distribution of elephants), ${ }^{\mathrm{b}}$ Total number of elephant MCP grids, ${ }^{\mathrm{c}}$ Percentage of total grid divided by total grid, Sb Gajah: distribution of elephants, Sb Man01: Distribution of respondents, Sb Man02: Distribution of settlements, Sb Man0102: Combined distribution respondents and settlements 
Table 3. Test the normality of data on all variables on elephants and human in Balai Raja and Tesso Nilo, Riau, Indonesia

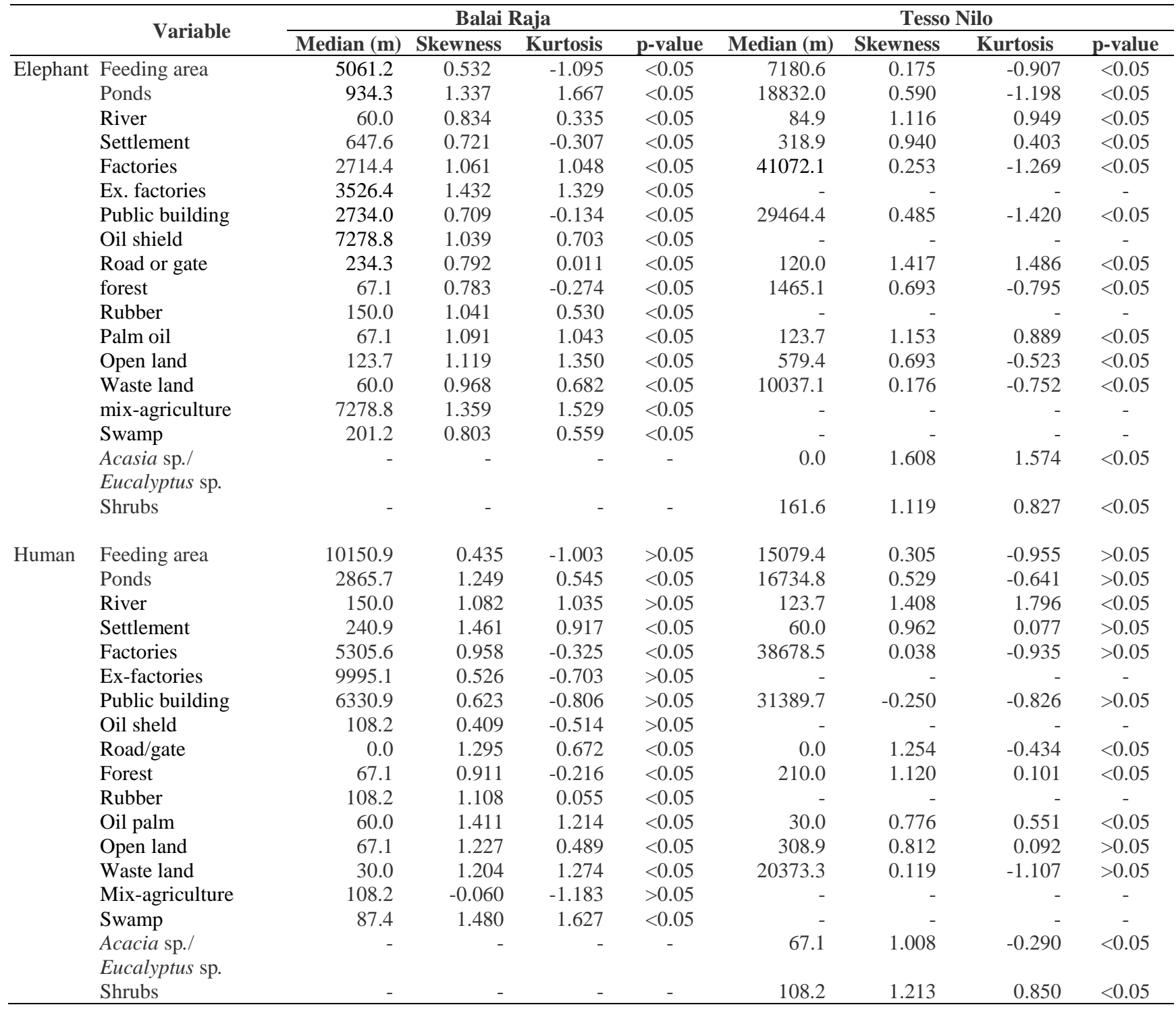

Variables that have the strongest (closest) relationship with the community at Balai Raja are open land, roads, and rubber gardens and whose connections are far apart are natural forests, water ponds, former factories and public facilities. From various variables related to community distribution, elephant feed locations have a strong correlation with factories $(0.915)$, public facilities $(0.721)$, former factories $(0.697)$ and water ponds $(0.605)$. Strong correlation also occurs between public facilities with former factories (0.691) and water pools (0.544). This means that when people access public facilities or factories, specifically the location is also close to former factories and water pools or when people access public facilities or factories, which are characterized by former factories and water pools. This position is usually a facility or location related to an oil company or sand mine in that location. In Tesso Nilo, rivers, Acacia and shrubs have the closest relationship with the Tesso Nilo community, then settlements, oil palm, and roads. The most distant relationship between the Tesso Nilo community and the resource variable is between the Tesso Nilo community and wasteland, public facilities, water ponds, and factories.

\section{Similarity index of niches in space and resources}

The similarity index of the niche is used by the Jaccard index, also called the Jaccard association index. In the context of the use of similarity indexes, the habitat space of Balai Raja (Desma elephant group) and Tesso Nilo (Angelina and Butet elephant groups) and the distribution of respondents and settlements in these two elephant pockets were mapped in a $2 \times 2 \mathrm{~km}^{2}$ grid. After that, the distribution points are determined based on each numbered grid. The grid number that has no distribution for all the components above, is omitted. Biodiversity Pro software is used to simplify work in determining this similarity index. 


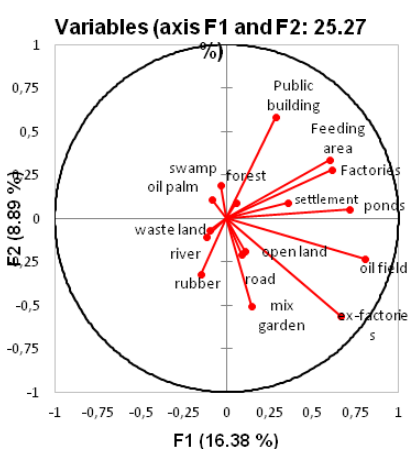

A

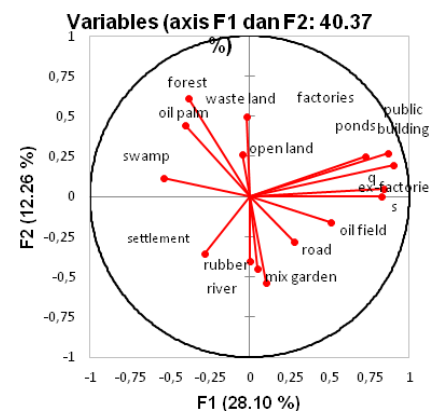

D

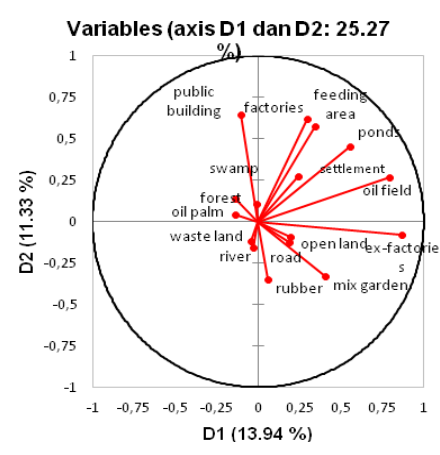

B

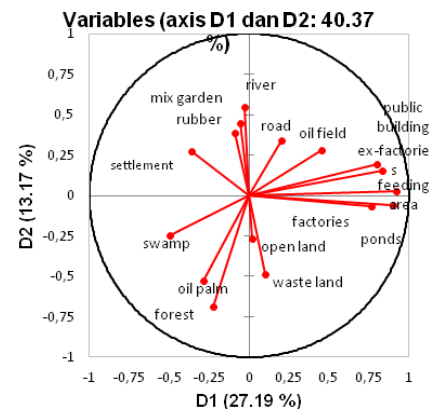

E

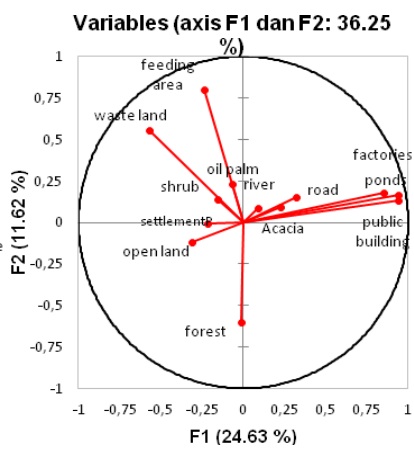

$\mathrm{C}$

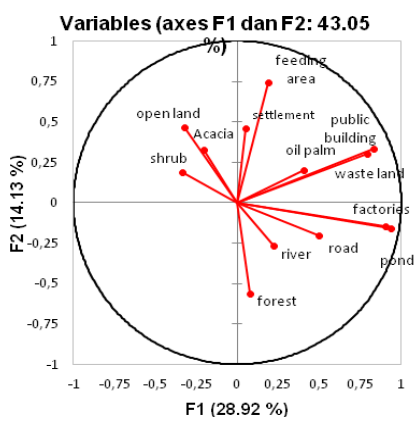

F

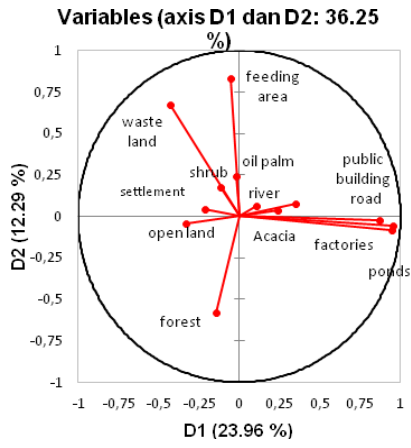

D

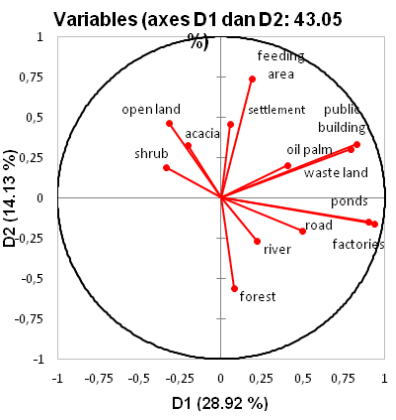

G

Figure 2. Result of PCA analysis on the resources in Balai Raja and Tesso Nilo, Riau, Indonesia in relating to elephant distribution inside or nearby the resources

Table 4. The value of similarity or association of space between Desma or Angelina-Butet and respondents and settlements in Balai Raja and Tesso Nilo, Riau, Indonesia with Biodiversity Pro software

\begin{tabular}{lcccc}
\hline Balai Raja & Desma & Man01 & Man02 & Man0102 \\
\hline Desma & $*$ & 17 & 38.7097 & 35.5932 \\
Man01 & $*$ & $*$ & 17.7778 & 52.2222 \\
Man02 & $*$ & $*$ & $*$ & 65.5556 \\
Man0102 & $*$ & $*$ & $*$ & $*$
\end{tabular}

\begin{tabular}{lcccc}
\hline \multicolumn{1}{c}{ Tesso Nilo } & $\begin{array}{c}\text { Angelina- } \\
\text { Butet }\end{array}$ & Man01 & Man02 & Man0102 \\
\hline Angelina-Butet & $*$ & 2.1818 & 6.1644 & 6.7485 \\
Man01 & $*$ & $*$ & 1.8692 & 37.3832 \\
Man02 & $*$ & $*$ & $*$ & 64.486 \\
Man0102 & $*$ & $*$ & $*$ & $*$ \\
\hline
\end{tabular}

Note: Man01 = distribution of respondents, Man02 = distribution of settlements, Man0102 = distribution of respondents and settlements

From the results of calculations with the Jaccard index, the grid removed for Balai Raja is 185 grids while Tesso Nilo is 614 grids. The grid removed is not used for the distribution of each component. For Desma and Balai Raja community represented by respondents, it was found that the similarity or space association was $17 \%$, then with the distribution of settlements having the same space $34.44 \%$. If respondents and settlements are combined and associated with Desma, the similarity value is $35.6 \%$. Then for Tesso Nilo, the Angelina and Butet groups juxtaposed with community respondents resulting in similarity or space association is $2.18 \%$. If Angelina and Butet are juxtaposed with the distribution of settlements, the similarity is only $6.16 \%$ and if the respondents of the community and settlements are united and juxtaposed with the distribution of Angelina and Butet, the similarity value is $6.7 \%$.

Table 4 and Figure 2. below describes the percentage of similarities between various components, especially between Desma and Angelina-Butet with respondents and the distribution of settlements identified as community areas in Balai Raja and Tesso Nilo.

The Jaccard index shows that the association between Balai Raja respondents and Desma is below 50\%, as well as the association between the combined data of respondents and settlements with Desma. Then in Tesso Nilo, the association showed far below $50 \%$ between Tesso Nilo elephants (Angelina and Butet) and the Tesso Nilo community. From these results, the differences between the elephants and humans in Balai Raja and Tesso Nilo are significantly based on space.

Overlapping analysis of niches is not only on the scale of space from the home range or activity of elephants and humans, but also from the magnitude of the use of resources. Identified resources refer to resources that have been focused on PCA analysis as variables. The resources in the PCA analysis are then divided into three categories of resources, namely infrastructure (factories, ex-factories, public facilities, settlements, oil fields and roads), needs for elephants (water ponds, natural forests, rivers and feed locations) and other land cover (rubber, oil palm, swamp, 
bush, open land, wasteland, mixed gardens and Acacia or Eucalyptus).

The analysis using resource data is not used or used in orthogonal values (0 and 1$)$ based on field records. Then the movement of elephants or human positions is calculated in the number of each grid $2 \times 2 \mathrm{~km} 2$ which overlaps the position of resources or from calculating distances of $0-30$ $\mathrm{m}$ between subjects of observation and resources, so as assuming the frequency of resource use by elephants or humans in that location. The Pianka Index analysis was used in the EcoSim 2012 software, but before analysis was carried out, all data in the variables were checked first by the Kolmogorov-Smirnov (K-S) test for the normality test.

From checking the K-S test, the frequency of use of each resource by Desma and Balai Raja community identified normal data $(>0.05)$ while the Tesso Nilo elephant and Tesso Nilo community were distributed to near normal (skewness-kurtosis values between-1.96-1.96). By using the Spearman (non parametric) correlation test, Desma elephant and Balai Raja community have a strong correlation (0.658). Butet and Angelina also had strong correlations with the Tesso Nilo people, which were 0.805 and 0.856 respectively.

Table 5 shows the frequency of the presence of each subject of observation (elephants and humans) on resources. Natural forests, rivers, oil palm plantations, roads, and open land are widely accessed by these three elephant groups in Balai Raja and Tesso Nilo. Acacia is more accessible to Butet than Angelina and mixed gardens are accessed by Desma. For Balai Raja and Tesso Nilo communities, the frequency of attendance is mostly carried out in settlements, oil palm, and roads. Wasteland, open land, swamps, and mixed gardens are more accessible to Balai Raja community than Tesso Nilo. Desma has more variation in the use of resources, such as wasteland (383 visits), where Tesso Nilo elephants do not use these resources, Desma also uses more open land than Tesso Nilo elephants. Butet and Angelina seem to be more familiar with using residential areas than Desma, and this location has a high risk of access.

Table 5. Use of resources (variables) in elephants and humans in the presence or absence of presence and frequency in Balai Raja and Tesso Nilo, Riau, Indonesia

\begin{tabular}{|c|c|c|c|c|c|c|c|c|c|c|}
\hline & $\begin{array}{c}\mathbf{G j} \\
\text { Desma }\end{array}$ & $\begin{array}{c}\mathbf{G j} \\
\text { Butet }\end{array}$ & $\begin{array}{c}\mathbf{G j} \\
\text { Angelina }\end{array}$ & $\begin{array}{l}\text { Man } \\
\text { Baja }\end{array}$ & $\begin{array}{l}\text { Man } \\
\text { Nilo } \\
\end{array}$ & $\begin{array}{c}\mathbf{G j} \\
\text { Desma }\end{array}$ & $\begin{array}{c}\mathbf{G j} \\
\text { Butet }\end{array}$ & $\begin{array}{c}\mathbf{G j} \\
\text { Angelina } \\
\end{array}$ & $\begin{array}{l}\text { Man } \\
\text { Baja }\end{array}$ & $\begin{array}{l}\text { Man } \\
\text { Nilo }\end{array}$ \\
\hline Ponds & 1 & 1 & 0 & 1 & 0 & 3 & 1 & 0 & 1 & 0 \\
\hline Ex-factories & 1 & 0 & 0 & 0 & 0 & 1 & 0 & 0 & 0 & 0 \\
\hline Public building & 1 & 0 & 0 & 1 & 1 & 14 & 0 & 0 & 5 & 1 \\
\hline Feeding area & 1 & 1 & 1 & 0 & 0 & 3 & 1 & 1 & 0 & 0 \\
\hline Rubber & 1 & 0 & 0 & 1 & 0 & 189 & 0 & 0 & 12 & 0 \\
\hline Mix agriculture & 1 & 0 & 0 & 1 & 0 & 532 & 0 & 0 & 23 & 0 \\
\hline Oil field & 0 & 0 & 0 & 0 & 0 & 0 & 0 & 0 & 0 & 0 \\
\hline Open land & 1 & 1 & 1 & 1 & 1 & 161 & 50 & 56 & 18 & 2 \\
\hline Wasteland & 1 & 0 & 0 & 1 & 0 & 383 & 0 & 0 & 36 & 0 \\
\hline Factories & 0 & 0 & 0 & 1 & 0 & 0 & 0 & 0 & 5 & 0 \\
\hline Settlement & 1 & 1 & 1 & 1 & 1 & 9 & 27 & 35 & 16 & 19 \\
\hline Oil palm & 1 & 1 & 1 & 1 & 1 & 292 & 180 & 215 & 29 & 21 \\
\hline River & 1 & 1 & 1 & 1 & 1 & 317 & 134 & 109 & 4 & 8 \\
\hline Forest & 1 & 1 & 1 & 1 & 1 & 436 & 82 & 168 & 1 & 3 \\
\hline Road & 1 & 1 & 1 & 1 & 1 & 83 & 139 & 94 & 58 & 63 \\
\hline Swamp/marsh & 1 & 0 & 0 & 1 & 0 & 60 & 0 & 0 & 14 & 0 \\
\hline Shrub/bush & 0 & 1 & 1 & 0 & 1 & 0 & 7 & 125 & 0 & 8 \\
\hline Acacia & 0 & 1 & 1 & 0 & 1 & 0 & 653 & 172 & 0 & 1 \\
\hline \multicolumn{2}{|c|}{ p-value $($ alpha $=0.05)$} & & & & & 0.135 & 0.04 & 0.04 & 0.220 & 0.03 \\
\hline
\end{tabular}

Table 6. Pianka Index value for elephants and humans based on the amount of resource use

\begin{tabular}{llllll}
\hline \multicolumn{1}{c}{ Components vs. Components } & Infrastuctures & Elephant needs & Forest cover 1 & Forest cover 2 \\
\hline Gj Desma & Gj Butet & 0.9826965 & 0.9228599 & 0.1252795 & 0.3837762 \\
Gj Desma & Gj Angelina & 0.9558864 & 0.8471034 & 0.4336904 & 0.1584357 \\
Gj Desma & Man Baja & 0.9803779 & 0.7463581 & 0.9019364 & 0.9978419 \\
Gj Desma & Man Nilo & 0.971752 & 0.6092185 & 0.4568453 & 0.0939871 \\
Gj Butet & Gj Angelina & 0.986487 & 0.7880892 & 0.5651448 & 0.531428 \\
Gj Butet & Man Baja & 0.990198 & 0.9277555 & 0.1920963 & 0.4428943 \\
Gj Butet & Man Nilo & 0.9947832 & 0.7464584 & 0.319353 & 0.3747013 \\
Gj Angelina & Man Baja & 0.9893851 & 0.6030485 & 0.6649957 & 0.1828416 \\
Gj Angelina & Man Nilo & 0.9978678 & 0.8598798 & 0.9622724 & 0.984515 \\
Man Baja & Man Nilo & 0.9940242 & 0.7048091 & 0.7004999 & 0.1084652 \\
\hline
\end{tabular}

Note: Gj: elephant, Man: human, Baja: Balai Raja, Nilo: Tesso Nilo 
From the analysis of the Pianka Index, it was found that in resource use, Desma with Balai Raja community had similar niches in the use of types of resources needed by elephants, infrastructure and other land covers (0.7460.980). Butet and Angelina have relatively the same niches as the Tesso Nilo community on the type of resources needed by elephants and infrastructure use (between 0.746 0.997). But Butet and the Tesso Nilo community are different niches for the use of land cover types (I and II, namely rubber, oil palm, open land, idle land, shrubs, and Acacia) (0.319 and 0.374) (Table 6). Butet seems to be more likely to use the Acacia forest type than other types of resources and the Tesso Nilo community prefers infrastructure with very few (not varied) choices of resources. Angelina is more varied in choosing resources so that for all types of resources, it is strongly associated with the Tesso Nilo community in resources use.

\section{Discussion}

Niches are generally known as the response of species or individuals to the distribution of natural resources and competition (competitors) (Schoener 2009). When the species interact with other organisms in accessing resources, and there is temporal and spatial competition, resulting in changes in certain factors in the species (Peterson et al. 2011). In the context of the niche of Hutchinson (1957), niches are multidimensional $\mathrm{N}$ spaces in which an organism lives in dividing its life from other organisms in terms of conditions of resources and environmental conditions. In the context of Hutchinson is a niche approach in spatial spectacles while Grinnel is in the context of ecological rules (Schluter 2000; Schoener 2009).

In the context of elephants, niches are seen from temporal and spatial dimensions of diet and habitat selection (Chase and Leibold 2003; Schoener 2009; Kleynhans et al. 2011; O'Kane et al. 2011). In the temporal niche context, some species have a high overlap of African elephants in the use of water pools, but generally, they avoid these elephants. This is due to interspecific competition and limited and localized resource availability. The division of time in the use of these resources is an herbivorous strategy where elephants are the strongest among others (Valeix et al. 2007).

In the context of $\mathrm{N}$-dimensional niches, several factors are identified, namely spatial or living area of species, temporally in the context of daily activity of species, distribution of feed and area of water, land cover, and rainfall. In various studies, the distribution of feed, temporal niches or the distribution of elephants with the influence of rainfall is the main thing studied (Valeix et al. 2007; Ahrestani et al. 2012). Elephant niches in various studies involve different seasons. In the study of feces, niche habitats are smaller in the wet season on elephants. This can be seen from the research conducted by Ahrestani et al. (2012) show that elephants and gaur have greater niche values but other mammals are in the dry phase, the value of the niche is greater. Not only season, but elephant niches are also influenced by other environments (Wiens et al. 2009). Research conducted by Martinez-Freiria et al.
(2016) take into account the conditions of air and humidity temperatures in areas of overlapping niches in the context of climate change.

The niche research at Balai Raja and Tesso Nilo take into account other things as environmental factors relating to conflict and the struggle for space and resources. This is more important with regard to efforts to reduce conflict or interspecific competition and optimize the lives of elephants and humans in these two locations. The niche research at Balai Raja and Tesso Nilo did not see any difference in seasons, because previous research showed that the movement of Sumatran elephants was not affected by the different seasons at Tesso Nilo. Then this was also reinforced by previous Sumatran elephant research in Seblat and Bukit Barisan Selatan which did not show the distribution of elephants influenced by the season (Sitompul 2011; Sukmantoro et al. 2013).

In a study conducted at Balai Raja and Tesso Nilo, the size of habitat in MCP showed a significant overlap of niches between elephant and human. At Balai Raja, precisely the space for elephant habitat is in the space of human habitat. However, the use of $2 \times 2 \mathrm{~km}^{2}$ for the classification of elephant and human distribution and the use of the Jaccard index shows that there is a significant niche partition between elephant and human at the Balai Raja and Tesso Nilo. Desma, Angelina and Butet built a real niche partition with humans based on the small number of grids showing overlapping distribution between the three elephant groups and communities in Balai Raja and Tesso Nilo. When viewed from the movement pattern of Desma, Angelina and Butet groups also show aggregation or gathering, while the spread of the community is more random or widespread. In Tesso Nilo, Angelina and Butet display a significantly separate distribution from humans, thus showing a natural avoidance between elephant and human. In this context, spatial niches occur spatially in elephant species associated with other species (Castelda 2008; Martinez-Freiria et al. 2016).

Overlapping niches occur between Desma, Angelina and humans at Balai Raja and Tesso Nilo in the use of resources. Almost all resources are used by elephant and human groups. However, PCA analysis shows more specifically. Overlapping niche resources occur between Desma and Balai Raja communities through open land, rubber gardens, roads, settlements, and rivers. Resource partitioning occurs in access to natural forests, swamps, oil palm plantations, wasteland and oil fields (Figure 2.A). In the context of overlapping resources, elephant conflict with humans has the potential to have high opportunities. Desma's group uses the resource space as a place to look for food or their necessities, while the community has the same goal. For example, open land at Balai Raja where people still access this land. Open land at the Balai Raja is characterized by short grass and shrub vegetation with an average height of 1 meter or open altogether without vegetation. This land was intentionally opened by being burned to target planted crops for the community's economy. Conflict occurs when the community in the processing of open land, elephants enters the location. 
Rubber gardens and settlements are also locations that are at high risk of conflict. In some places, elephants damage rubber gardens, especially can eat rubber leaves on young plants and step on young saplings or seedlings in one garden area (Sukmantoro et al. 2013; Chen et al. 2016). Rivers and roads are relatively neutral accessed by Desma and the community because they are transported or not accessed by Balai Raja

Resource partitioning happened to Desma and Balai Raja community. For Desma, natural forests and swamps are areas that need to be maintained because they are a place to get food, water and minerals, and the community does not access this location. Partitions occur on wasteland because wasteland is not used by the community or unused land, which is in short grass and bush vegetation with an average height of 1 meter. The community does not use this because it is used elephants intensively in this area regularly so they leave this land because of conflict or infertile land. For the people of Balai Raja, the partition of niches with elephants is in the oil fields, but this access is not for the general public but only oil company workers who have access to this location.

At Tesso Nilo, overlapping niche resources for Angelina, Butet and communities occur in Acacia, roads, rivers, oil palm, settlements and shrubs. While niche partitions are only on open land as an area of Tesso Nilo elephant activity. Acacia is a location to live together in a neutral context, elephants can use this forest area and companies and communities are not disadvantaged regarding elephants not using Acacia so that they are not considered pests. Angelina and Butet are not too close to access to natural forests (except in habitat selection, Butet is more likely to choose natural forests (Sukmantoro et al. 2019), because natural forests are shrinking dramatically, and the remaining natural forests in national parks appear to be blocked by human activities, because it is seen that natural forest is the closest to access

The biggest risk for elephants and humans is the overlapping use of oil palm plantations and settlements. In Tesso Nilo, oil palm plantations are a contested resource. Records of elephant and human death conflicts in Tesso Nilo are dominant in oil palm plantations, settlements and partly in Acacia forests (elephant deaths in Acacia forests are actually due to poisoning in oil palm plantations or hunting motives) (Kuncoro et al. 2014). Niche partitions occur in open fields by Angelina and Butet. The Tesso Nilo elephant groups both access these resources where the Tesso Nilo community does not access them. Open land is indeed an opportunity to be planted by the community, but usually conflicts with elephants occur. Open land is also inside the Acacia concession, after harvest, the land becomes open and overgrown with grass and is not accessed by the community. Some research records inform elephants to use this location from tracing, dirt and direct encounters. Location of open land is like a savanna with a relatively large number and spread. This location is also suitable for several types of mammals (Young et al. 2009; Alikodra 2010; Sitompul 2011; Zyambo 2016).

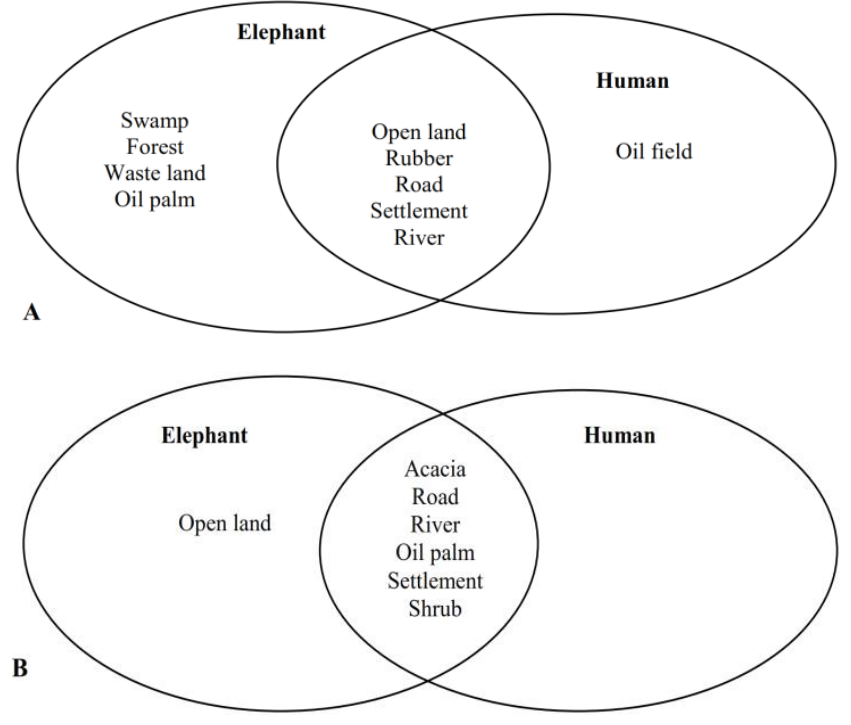

Figure 3. Overlaying and partitioning of resource niches between elephant and human at Balai Raja (A) and Tesso Nilo (B) from PCA analysis results

In accessing resources (analysis with the Pianka index (Mouillot et al. 2005), Desma with Balai Raja community and Angelina and Butet with the Tesso Nilo community have a similarity in the use of resources. The types of resources used tend to be the same or not significantly different even though some more intensively visited resources were identified. Elephants in Balai Raja and Tesso Nilo also use resources that support elephants and access infrastructure, although not in high intensity, which is also intensively accessed by humans.

Desma and Balai Raja community have a strong correlation in the similarity of resource niches in terms of the resources needed for elephants, infrastructure and other land covers. Angelina and the Tesso Nilo community also have niche similarities in the utilization of the resources needed for elephants, infrastructure and other land covers. For Butet and the Tesso Nilo community, the resources required by elephants and infrastructure have a strong correlation in the similarity of niches but the correlation is weak in other land coverings. The reason for the correlation is weak because Butet has more access to Acacia than other land covers. A visit to this location in the GPS Collar record is 653 times in one period of installation of this tool.

In conclusion, Desma, Angelina and Butet groups live in the same habitat space as Balai Raja and Tesso Nilo communities. However, specifically, they differ in space or significant niche partitions occur. Space differences because most likely elephants and humans instinctively try to separate themselves between the two due to high and prolonged conflicts. In general, the resources accessed by elephants and humans at Balai Raja and Tesso Nilo are the same, although, in the end, the elephants are more determined in natural forests, swamps and waste areas where human activities are few or avoided. In the selection of habitats, natural forests and swamps are the resources most chosen by the Desma elephant group (Sukmantoro et 
al. 2019). Other resources that are close to Desma, namely open land, rubber plantations, roads, settlements, and rivers are the locations of conflicts because many people access this area. This overlap of niches results in conflicts, especially settlements.

In the Angelina and Butet groups, open land is a strong niche between elephant and human. The Tesso Nilo community does not use open land for daily activities, unless they do it in the context of clearing land for gardens. In general, open land is left by the community, especially in areas of high elephant movement. Then, open land was identified in locations after Acacia harvesting, where elephants visited this location to get food from young grasses which naturally grew after harvesting. Acacia, roads, rivers, oil palm plantations, settlements, and shrubs are resources that overlap with humans. From the results of the study, although Angelina and Butet's clay overlapped with some use of resources with humans, space can be separated, so they can avoid conflict. It's also a neutral space where there is no loss between the two accessing this resource.

In the strategy of reducing elephant-human conflict, niche partitions can be a condition for reducing conflict or decreasing interspecific competition. So that management of forest, swamp, idle land, and open land resources is very important for the elephant group to live more and activities in this area. This management strategy is called habitat development, namely enrichment of needs for elephants (food, water, and minerals). The identification and zoning of these resources management become important and the community accepts this area for elephant needs. Other resources that overlap with humans are also identified where some can be used for elephant habitat space, especially spaces that partition with humans. Resources that have a high risk of conflicts such as oil palm plantations, rubber gardens, and settlements are sterile spaces for elephants, or oil palm and rubber plantations as a space for movement for elephants. Conflicts can be overcome by the existence of conflict mitigation teams or by using physical or psychological barriers in agreed and safe locations for elephants.

\section{ACKNOWLEDGEMENTS}

We express our gratitude to the Ministry of Environment and Forestry, Indonesian Republic, WWF US, AREAS, WWF Indonesia, and Bogor Agricultural University, Indonesia which gave supported in many aspects related to this research. We also thank Fadlan Pramatana (GIS expert), the all individuals field team, especially the GPS Collar installation team and the WWF elephant patrol team, the Tesso Nilo Foundation, the Tesso Nilo National Park Authority, BKSDA Riau section III and colleagues who individually assisted in the research.

\section{REFERENCES}

Ahrestani FS, Heitkonig IMA, Prins HHT. 2012. Diet and habitat-niche relationships within an assemblage of large herbivores in a seasonal tropical forest. J Trop Ecol 28: 385-394.

Akhtar H. 2017. How to overcome abnormally distributed data https: //www.semestapsikometrika.com/2017/12/mengatasi-data-tidaknormal.html. [Indonesian]

Alikodra HS. 2010. Technique for managing wildlife in order to maintain Indonesia's biodiversity. IPB Press, Bogor. [Indonesian]

Azad M.2006. Mammal diversity and conservation in a secondary forest in Peninsular Malaysia. Biodiv Conserv 15: 1013-1025.

Castelda SM. 2008. Waterhole Dynamics and Chemical Signals of African Elephants (Loxodonta africana) [Thesis]. Georgia Southern University, Geogia, USA.

Chase JM, Leibold MA. 2003. Ecological Niches: Linking Classical and Contemporary Approaches.. University of Chicago Press, Chicago, USA.

Chen Y, Marino J, Chen Y, Tao Q, Sullivan CD, Shi K, MacDonald DW. 2016. Predicting Hotspots of Human-Elephant Conflict to Inform Mitigation Strategies in Xishuangbanna, Southwest China. PloS One. DOI: 10.1371/journal.pone.0162035

Desai AA, Riddle HS. 2015. Human-elephant conflict in Asia. US Fish and Wildlife Service report, Washington, D.C.

deSilva S, Weerathunga US, Pushpakumara TV. 2014. Morphometrics and behavior of a wild Asian elephant exhibiting disproportionate dwarfism. BMC Res Notes 7: 2-7.

Feng L, Li Z. 2005. Habitat selection by asian elephant (Elephas maximus) in Xishuangbanna, Yunnan, China. Acta Theriologica Sinica 25 (3): 229-236.

Gotelli NJ, Ellison AM. 2004. A Primer of Ecological Statistics. Sinauer Associates, Inc., Sunderland, MA.

Hedges S, Tyson MJ, Sitompul AF, Kinnaird MF, Gunaryadi D, Aslan B. 2005. Distribution, status and conservation needs of Asian elephant (Elephas maximus) in Lampung Province, Sumatra, Indonesia. Biol Conserv 124: 35-48.

James FC, McCulloch CE. 1990. Multivariate analysis in ecology and systematics: Panacea or Pandora's Box? Ann Rev Ecol Syst 2: 129166.

Janžekovič F, Novak T. 2012. PCA - A Powerful Method for Analyze Ecological Niches, Principal Component Analysis-Multidisciplinary Applications. IntechOpen, London. DOI: 10.5772/38538.

Kleynhans EJ, Jolles AE, Bos MRE, Olf H. 2011. Resource partitioning along multiple niche dimensions in differently sized African savanna grazers. Oikos 120 (4): 591-600.

Krebs CJ. 1999. Ecological Methodology, 2nd ed. Benjamin/Cummings, Menlo Park, CA.

Legendre P, Legendre L.1998. Numerical Ecology. Elsevier. Amsterdam.

Leibold MA, Mcpeek MA. 2006. Coexistence of the niche and neutral perspectives in community ecology. Ecology 87 (6): 1399-1410.

Ludwig, JA, Reynolds, JF. 1988. Statistical Ecology: A Primer on Methods and Computing. Wiley, New York.

Margono B, Turubanova S, Zhuravleva I, Potapov P, Tyukavina A, Baccini A, Goetz S, Hansen M. 2012. Mapping and monitoring deforestation and forest degradation in Sumatra (Indonesia) using Landsat time series data sets from 1990 to 2010. Environ Res Lett. 7: 034010. DOI: 10.1088/1748-9326/7/3/034010

Martinez-Freiria F, Tarroso P, Rebelo H, Brito JC. 2016. Contemporary niche contraction affects climate change predictions for elephants and giraffes. Divers Distrib 22: 432-444.

Mouillot D, Stubbs W, Dumay MFO, Tomasini JA, Wilson JB, Chi TB. 2005. Niche overlap estimates based on quantitative functional traits: a new family of non-parametric indices. Oecologia 145: 345-353.

O'Kane CAJ, Duffy KJ, Page BR, Macdonald DW. 2011. Overlap and seasonal shifts in use of woody plant species amongst a guild of savanna browsers. J Trop Ecol 27: 249-258.

Pan W, Lin L, Luo A, Zhang L. 2009. Corridor use by Asian elephants. Integr Zool 4: 220-231.

Peterson AT, Sobedron J. 2012. Species distribution modeling and ecological niche modeling: Getting the concepts right. Natureza \& Conservação 10 (2): 102-107. 
Peterson AT, Soberon J, Pearson RG, Anderson RB, Martinez-Meyer E, Nakamura M, Araujo MB. 2011. Ecological Niches and Geographic Distributions. Princeton University Press, Princeton, USA.

Polansky L, Douglas-hamilton, Wittemyer G. 2013. Using diel movement behavior to infer foraging strategies related to ecological and social factors in elephants. Movement Ecol 1: 1-13.

Pradhan NMB, Wegge P.2007. Dry season habitat selection by a recolonizing population of Asian elephants Elephas maximus in lowland Nepal. Acta Theriologica 52: 205-214.

Robertson MP, Caithness N, Villet MH. 2001. A PCA-based modelling technique for predicting environmental suitability for organisms from presence records. Divers Distrib 7: 15-27.

Rood E, Ganie AA, Nijman V. 2010. Using presence-only modelling to predict Asian elephant habitat use in a tropical forest landscape: implications for conservation. Divers Distrib 16: 975-984.

Schluter D. 2000. Ecological Character Displacement in Adaptive Radiation. the Amer Nat 156: 4-16.

Schoener, Thomas W. 2009. Ecological niche. in the Princeton guide to ecology. Ed. Carpenter S, Levin S. Guide to Ecology. Princeton University Press, Princeton, USA. .

Senthilkumar K, Mathialagan P, Manivannan C, Gomathinayagam S. 2016. Human-elephant conflict: case study from Tamil Nadu. Intl J Sci 5 (6): 445-448.

SitompulAF. 2011. Ecology and Conservation of Sumatran Elephants (Elephas maximus sumatranus) in Sumatra, Indonesia. [Dissertation], Environmental Conservation. University of Massachusetts, Amherst, MA.
Songer M, Sampson C, Williams C, Forrest J, Gyeltshen K, Huy K, Sharma A, Gopala A, Budiman, Sadikin H, et al. 2012. Mapping habitat and deforestation in WWF Elephant Priority Landscapes. Gajah 36: 3-10.

Sukmantoro W, Purastuti E, Samsuardi, Sudibyo A, Fadli N. 2013. Installation and study on the use of GPS Collar on Sumatran Elephant Elephas maximus sumatranus in Tesso Nilo National Park, Riau Province (2007-2009). WWF Indonesia-Areas Report, Pekanbaru.

Sukmantoro YW, Alikodra HS, Kartono AP, Efranjah. 2019. Distribution and habitat preferences of Sumatran elephant (Elephas maximus sumatranus) in Riau, Indonesia. Biodiversitas 20 (1): 226-235.

Uryu Y, Mott C, Foead N, Yulianti K, Setiabudi, Takakai F, Nursamsu, Sunarto, Purastuti E, Fadhil N, Hutajulu CMB, Jaenicke J, Hatano R, Siegert F, Stuwe M. 2008. Deforestation, forest degradation, biodiversity loss, and $\mathrm{CO}_{2}$ emission in Riau Sumatra, Indonesia. Technical Report. WWF Indonesia, Jakarta.

Valeix M, Chamaille-Jammes E, Fritz H. 2007. Interference competition and temporal niche shifts: elephants and herbivore communities at waterholes. Oecologia 153: 739-748.

Wiens JA, Stralberg D, Jongsomjit D, Howell CA, Snyder MA. 2009. Niches, models, and climate change: assessing the assumptions and uncertainties. Proc Nat Acad Sci USA 106: 19729-19736.

Young KD, Ferreira SM, van Aarde RJ. 2009. Elephant spatial use in wet and dry savannas of southern Africa. J Zool 1-17.

Zyambo P. 2016. Woodland conversion by elephants in Africa: The search for causal factors, processes, mechanisms and management strategies. Open J Ecol 6: 93-101. 